\title{
The Effect of Online vs. Offline Flipped Instruction on EFL Learners' Writing Ability
}

\author{
Ali Rahimi \\ School of Social Sciences and Languages \\ VIT University \\ Vellore, Tamil Nadu, India \\ \& \\ MortezaHasheminasab \\ English Department \\ University of Kashan \\ Kashan, Iran
}

\section{Article History \\ Received: $\quad 07 / 10 / 2020$ \\ Reviewed: $\quad 07 / 17 / 2020$ \\ Accepted: $\quad 10 / 29 / 2020$}

\section{Keywords:}

Computer Assisted Language Learning (CALL), E-learning, EFL, Flipped Instruction, Writing Ability

DOI:

https://doi.org/10.33508/bw.v8i2.2607

\begin{abstract}
This study aimed at examining the effectiveness of computer-assisted flipped instruction on the writing ability of upper-intermediate Iranian EFL learners and their attitudes toward it. A mixed-method approach was used. A quantitative method enjoying the quasiexperimental pretest-posttest design was used. Twenty participants were selected based on the convenient sampling method and were divided into an online flipped instruction group $(\mathrm{N}=10)$ and an offline flipped instruction group ( $N=10)$. A paired sample t-test and independent samples t-test were used to analyze the obtained data. The results showed that the learners who received online flipped instruction outperformed those who received offline flipped instruction, regarding their performance on the posttest. According to the findings of this study, it was argued that the learners in the online group had a positive attitude toward this method
\end{abstract}

\section{Introduction}

During the past few years, we have language learning and teaching are the areas witnessed a gradual and, at the same time, rapid development in the field of language learning through computer-assisted language learning programs in a simple too complicated forms presented to users with varying levels of language competency. Any kind of coming technology aims at leading that have seen significant alterations due to immediate promotions of technology. The introduction and development of computers created a new concept in this field of technology entitled "Inverted or Flipped Classroom," which quickly became popular throughout the world.

to fresh prospects in pedagogy, and 
With the progress of the Internet and technology, the role of computer-assisted language learning has become more significant and taken the researchers' attention in dealing with the impact of computers and the Internet in learning. For example, Chapelle and Jamieson (1986) pointed out that instructors need to understand how CALL can best be used to offer practical instruction to language learners. Innovation in technologies relating to computer and online interactions, improvements in telecommunication and information technology, and the growing market of computer technology gave rise to the utilization of computer technology as an always-available device for teaching and learning languages. Various investigations on language teaching have emphasized using these technologies in teaching because learning a new language requires and demands interaction and autonomy, two basic notions in computer-assisted Language Learning. Due to the rapid alterations in this technology and because of continuous improvements in forms of their usage, teachers, researchers, and scholars have tried to find other new applications of this utility that may be helpful and advantageous in teaching languages.

These days, language learning and teaching cannot be regarded as separate from technology (Warschauer \& Meskill, 2000). This dependency had existed since a long time ago when the grammar-translation approach was based on applying blackboard. Later this continued in more modern forms of technology flourished in computer and mobile programs such as the audio-lingual method and the cognitive and sociolinguistic approaches to language teaching, the prerequisite of which was computer-aided programs implemented in the teaching situations. This forward movement of technology led to introducing the Computer Assisted Language Learning in the 1990s.Salaberry (2001), in opposition to the application of technology in education though, insists on the traditional forms of pedagogy in teaching language; and Beatty (2013) similarly believes that teachers should not consider using technology in the teaching process while nothing has been proved about its usefulness. Kiernan and Aizawa (2004), exploring the efficiency of language learning tools, conclude that the best way for learning a second language is task-based learning, not technology-based learning. They found the prominence of face-to-face activities over the technologybased ones in promoting the learners' linguistic performance.

Hubbard (2009)notes that while the early promise of computer-assisted language teaching (CALT) has not been achieved to revolutionize second-language learning, there has been a fascinating amount of development in the last quarter-century. This is not only because of language learned from research and practice but also due to the fast changes that occurred in the technology. Timuçin (2006)suggests that institutional L2 teachers are focused on the possibility of incorporating teaching technology. Yet the method of using emerging technology and handling rapid changes is far from being a simple task. The successful use of emerging technology needs significant effort, in particular by the administrative people involved in this process.

There has been a steady but persistent change in the way learning is done in a classroom over the last decades or so. With the introduction of modern pedagogical methods, more and more faculty members are implementing a blended approach to learning experience for students(Hughes \& 
Bruce, 2013).The "blended learning" approach puts together the persuasive elements of the online, classroom, and social learning to improve students' involvement and interaction in a classroom. Also, it aims to accomplish the expected learning success steps. The "Flipped Classroom" is a sort of blended learning approach where the curriculum and knowledge mastering function fall back to the students. With these strategies, the role of the teacher has gone through a metamorphosis from being the "sage on board" to being the "guide on the hand," and classes are now shifting from a conventional and passive teacher-centered learning atmosphere to an engaging studentcentered one with the teachers taking on the role of facilitators.

Technology does not positively impact teaching all the time, though face-to-face instruction is often not the ideal way to train. Researchers have recently discussed the value of learning a language through social and productive acquisition rather than through comprehension and memorization (Brown, 2014).Flipped learning as a part of the blended classroom is considered as a combination between both E-learning and face-to-face learning.

The flipped classroom is a technique that tra nsforms classroom experience from a classr oom area toanywhere, and is not timelimited ; learners can use the tools at any time and more than one time. The most suitable method for second language acquisition (SLA) is considered to happen outside the classrooms without the constraints of any educational context (Brown, 2014).Flipped instruction is not a universal teaching method; it tries to involve all learners in the educational process. The fundamental idea and approach to presenting flipped content involve the creation of a pre-recorded video that covers the basic theoretical principles of a given lesson that students can view at their leisure outside of the classroom to obtain some insight into the subject discussed in the next lecture(Bishop, 2013).This opportunity supports the teacher by opening up classroom resources, which can be used for constructive learning events such as inclass conversations, questions answered, and community activities.

Considering the research done on writing and flipped instruction so far, the purpose of this study is to find whether flipped classes through computer-assisted instruction have any effect on upperintermediate EFL learners' writing ability.

Two research questions are supporting the objectives of the present study:

1. Does the online flipped model of instruction have any significant influence on upper-intermediate Iranian EFL learners' writing ability?

2. What are upper-intermediate Iranian EFL learners' attitudes toward the implementation of flipped instruction model?

\section{Literature Review}

Lage et al. (2000)published a study titled "Inverting the Classroom: A Gateway to Creating an Inclusive Learning Environment." According to this study, students' access to multimedia and promoting the use of multimedia tools for the faculty means that reaching students with specific learning styles is no longer restricted by time constraints or at risk of losing coverage of the course. They design a strategy that is used in two microeconomics classes at the freshman level, and both teachers and students discuss method perceptions. The aim is to meet students with different learning styles by offering opportunities for students to use in non-class 
learning, and through a lot of exercises and activities to improve engagement between learners and instructors inside of class. The researchers noted that this approach increased the amount of burden put on the student, and additional resources were made available to the students to assist in the analysis of the subject. Help and openness were also built-in, such as the availability of teachers to reply online chat room questions, interactive quizzes for the students to evaluate their skills, and worksheets for checking homework completion. Inside the classroom, learners' practice on experiments, lab exercises, held discussions, and completed hands-on activities under the guidance of the teacher.

Overall, student emotions and expectations of this approach and course were optimistic, and teachers reported a rise in learners' use of this program. The researchers suggested a potential explanation for the increase in stimulation, as this style of classroom permitted students to take control of their learning. The teachers observed that learners were increasingly more confident asking questions in class, likely due to the "increase in opportunities for one-on-one contact with the instructor." From the teachers' perspective, the course was considerably more motivating to teach. The researchers, comparing this approach and program with a conventional classroom, noted that "it could be that lower student participation is expected in the inverted classroom." Researchers noted that one positive point of this method is the increased potential for interaction between faculty and students. Such interaction is useful in two ways: the learner can automatically clear up any ambiguity, and the teacher can screen the results and understanding (Lage et al., 2000).
A large number of papers have been published to illustrate the beneficial impact of using the flipped classroom approach in all academic modules. Wentland (2004)grouped different teaching approaches according to their effectiveness in separate classifications, including the instructional goals of Bloom. The classification was based on whether the approach promoted student or teacheroriented action, whether it focused on technology, whether it included individual or group-oriented work, and whether it was time-consuming or time-saving. The research analyzed the methodologies used in teaching economics, including the CPS approach, service learning, lecturing, lecturing plus, interactive (role-play), inverted classroom, technology-based, case studies, and tests, presentations, and drama. The study found that the inverted classroom had met cognitive and affective goals but not necessarily the psychomotor (hands-on) objective from Bloom's taxonomy of educational purposes. The research also concluded that there is a student-oriented practice in the flipped classroom where teachers play a more supporting role while students take an active role in the learning process. Finally, the study concluded that using the inverted instruction required both person and community-oriented action, and categorized this approach as time-saving rather than time-consuming. It indicates that this approach can be used in a reasonably short time to convey much information (Wentland, 2004).

Al-Harbi and Alshumaimeri (2016) decided to use the flipped classroom strategy to teach English grammar to investigate its effect on the results, expectations and attitudes of secondary school students towards independent English language learning. For this analysis, 
the researchers applied the flipped classroom strategy by selecting videos based on the textbook of the students and uploading those videos to the Edmodo website before starting each lesson. The purpose of doing this method wasto provide opportunities for active learning interactions. The experimental group included 20 learners, who were required to watch the videos and learn on their own and to come to class ready for clarification. The experimental group practiced what they had learned under the teacher's supervision by completing collaborative and competitive tasks in groups or pairs. Besides, the control group was 23 learners and received only inclass traditional teaching. They were taught grammatical lessons without watching videos. The statistical analysis of the posttest showed that implementing the flipped classroom strategy had a significant role in improving the students' grammar performance. Moreover, the mean score of the experimental group was more than that of the control group, but this difference was not statistically significant. Responses from the participants to a questionnaire and semistructured interviews showed positive attitudes about using the flipped classroom approach in the EFL class, and they were pleased with this teaching process.

In a recent study, Hung (2015)attempted to implement flipped teaching into language classrooms that use a
WebQuest active learning strategy. The object of this research was to explore the impacts of flipped instruction on English language learners' academic performance, participation levels, and learning attitudes. The researcher adopted a quasiexperimental design, and three different formats for flipped teaching were employed in this study.

In a study conducted by Enfield (2013), the influence of the flipped classroom teaching model on multimedia undergraduate students at CSUN has been investigated. This study has been done on two classes at California State University, Northridge. Participants in this study stated that the method of flipped instruction engaged them in learning experiences, and it has a significant role in learning new content. Besides, it helped learners in enhancing self-efficacy in their ability to learn by them-selves and independently.

Bhagat et al. (2016)investigated the effect of the flipped teaching approach on the performance and motivation of the students. The researchers grouped students into three separate groups, and the total number of participants was 82. Researchers benefitted from pretests and posttests in this analysis. The findings demonstrated the positive role that the flipped teaching approach plays, particularly on average students.

\section{Participants}

To collect the required data, a total of twenty Iranian learners at the upperintermediate level of language proficiency took part in this study. Their ages rangedfrom 18 to 34 years old, and they studied at an English language institute. The approach of sample selection was based on

\section{Methods}

convenience, and allparticipants were female.

These participants were taking the course of Topnotch3B and were divided into two groups of online (experimental group) and offline instruction (control group). Both groups have been homogenized because they were selected based on their 
performance on the Oxford Placement Test (OPT).

\section{Procedure}

After dividing the participants into experimental and control groups, they took an OPT and were homogenized accordingly.

In contrast, the control group was presented with the same passages in the class on a PowerPoint platform, which were given to them through teacher presentations in the class and a copy of which they could have at home. After the treatment sessions, which lasted for six weeks, both groups took a posttest. It is worth mentioning that the pretest and posttest were in parallel forms.

\section{Instruments}

Oxford Placement Test (OPT). Oxford Placement Test, as a test of proficiency homogeneity, was administered multiple choice items on grammar, vocabulary, and reading comprehension. They were allotted to take it in 40 minutes. This test was used to homogenize the learners in two groups of this study.

Pretest and Posttests. Two writing tests were administered in this study, one for pretest and the other one for the posttest of the study. Both tests had the same writing prompts to make sure of the reliability and validity of the research. The prompts were selected from the Top Notch 3B final test manual, and to ensure the content validity of the tests, the participants were asked to write a 150 -word essay on that. The essays were corrected, and the number of grammatical errors was recorded for further analysis. The essays were scored based on at the beginning of the term. This test has 60

Then a writing test was given to them as the pretest. As their treatment, the experimental group received the flipped model of instruction with a selection of writing tasks taken from different course books on a computer-assisted platform, i.e., WhatsApp Kentucky Analytical Writing Scoring Rubric. The reason behind choosing this rubric was the fact that it was a valid scoring reference for language teachers, and it provided analytic scoring criteria including coherence, structure, cohesion, etc., which could add to the consistency of scoring and, in turn, improve the reliability of the scores. Since a single rater scored the drafts, there was a need for intra-rater reliability of the ratings, which was calculated to be 0.83 .

Interview. An interview was conducted to explore the attitudes of the learners toward the computer-assisted flipped learning method used in each group. Thus, the researcher conducted a semi-structured interview to explore their attitudes toward the issue. The reason behind the adoption of the semi-structured interview was that in the first two cases of interview sessions, the learners did not elaborate on the issues raised in the structured interview, and the researcher had to ask several detailed questions which could affect the subjectivity of the interview. Accordingly, the researcher decided to conduct a semistructured interview considering the ages of the participants and let them pour out whatever they thought about their experience of the new method.

\section{Results}

According to the results depicted in Table 1, variables' distributions on the essential central index (mean) and the most important dispersion index (standard deviation) are indicated. The table sheds light on the mean in the offline group, which is 40.90 , with SD of 7.125. The mean score of the online group is 41.90, with SD of 6.026. Moreover, the minimum and maximum scores of the offline group, according to the table, are 
(minimum, 29.00) and (maximum, 55.00).

and 52.00, respectively.

These values for the online group are 33.00

Table 1.

Descriptive statistics of OPT results

\begin{tabular}{llllll}
\hline & $\mathrm{N}$ & Mean & $\begin{array}{l}\text { Std. } \\
\text { Deviation }\end{array}$ & Minimum & Maximum \\
\hline Level-offline & 10 & 40.90 & 7.125 & 29.00 & 55.00 \\
Level-online & 10 & 41.90 & 6.026 & 33.00 & 52.00 \\
Valid N (listwise) & 10 & & & & \\
\hline
\end{tabular}

\section{Descriptive Findings}

To become more familiar with the nature of the research variables, it is necessary to describe them before analyzing the data because the statistical description of the data precedes the statistical inference and helps to identify the patterns that govern the data. In this section, as described above, some descriptive characteristics of the research variables are examined using some central and dispersion indices

Table 2.

Descriptive statistics of the research variables

\begin{tabular}{|c|c|c|c|c|c|c|c|}
\hline \multirow[t]{2}{*}{ Variable } & \multirow[t]{2}{*}{$\mathrm{N}$} & \multirow[t]{2}{*}{ Mean } & \multirow[t]{2}{*}{$\begin{array}{l}\text { Std. } \\
\text { Deviation }\end{array}$} & \multirow[t]{2}{*}{ Minimum } & \multirow[t]{2}{*}{ Maximum } & \multicolumn{2}{|c|}{$\begin{array}{l}95 \% \text { Confidence } \\
\text { Interval of the } \\
\text { Difference }\end{array}$} \\
\hline & & & & & & Lower & Upper \\
\hline Pretest offline & 10 & 13.70 & 1.16 & 12.00 & 16.00 & 12.98 & 14.42 \\
\hline Posttest offline & 10 & 14.60 & 0.669 & 14.00 & 16.00 & 14.83 & 16.17 \\
\hline Pretest online & 10 & 13.40 & 0.97 & 12.00 & 15.00 & 12.80 & 14.00 \\
\hline Posttest online & 10 & 16.00 & 0.816 & 15.00 & 17.00 & 14.71 & 15.89 \\
\hline $\begin{array}{l}\text { Valid N } \\
\text { (listwise) }\end{array}$ & 10 & & & & & & \\
\hline
\end{tabular}

According to table 2, the mean score of the pretest in the offline group is 13.70 , and in the online group, this value is 13.40. On the other hand, the values of the mean for posttests in both groups are 14.60 and 16.00, respectively.

\section{Inferential analysis}

In the inferential analysis section, the normality of the variables is examined using the Kolmogorov-Smirnov test. The relationship between the dependent variable and independent variables is investigated, and the research hypotheses for

confirmation or disapproval are

investigated.

\section{Check for the normality of variables}

To check the normality of the research variables, using the Kolmogorov-Smirnov test, the null hypothesis $\left(\mathrm{H}_{0}\right)$ indicates that the variable is normal and the opposite assumption $\left(\mathrm{H}_{1}\right)$ indicates that the variable is not normal. The following table is the output of this test:

$\mathrm{H}_{0}$ : Data distribution is normal.

$\mathrm{H}_{1}$ : Data distribution is not normal. 
Table 3

One-Sample Kolmogorov-Smirnov Test

\begin{tabular}{|c|c|c|c|c|c|}
\hline & & \multicolumn{4}{|c|}{ Pretest offline Posttest offline Pretest online Posttest online } \\
\hline $\mathrm{N}$ & & 10 & 10 & 10 & 10 \\
\hline \multirow[t]{2}{*}{ Normal Parameters ${ }^{a}$} & Mean & 13.7000 & 15.5000 & 13.4000 & 15.3000 \\
\hline & Std. Devia & 1.15950 & 1.08012 & .96609 & .94868 \\
\hline \multirow[t]{3}{*}{ Most Extreme Differences } & Absolute & .227 & .178 & .233 & .224 \\
\hline & Positive & .227 & .178 & .167 & .224 \\
\hline & Negative & -.173 & -.178 & -.233 & -.176 \\
\hline Kolmogorov-Smirnov Z & & .718 & .564 & .736 & .709 \\
\hline Asymp. Sig. (2-tailed) & & .681 & .908 & .651 & .697 \\
\hline
\end{tabular}

Considering the significance level values obtained in table 3 which are all greater than 5\%, the null hypothesis that the distribution of samples is normal at the $5 \%$ error level is confirmed, meaning that there is not a significant difference between the distribution of samples and the normal distribution of data. Thus, given the central limit states that when the number of samples is greater than 30 , it shifts to normal, it can be concluded that the distribution of data is normal. Thus, it can be concluded that the Table 4 Independent Samples Test

\begin{tabular}{|c|c|c|c|c|c|c|c|c|}
\hline & $\begin{array}{l}\text { Levene's } \\
\text { Test for } \\
\text { Equality of } \\
\text { Variances }\end{array}$ & \multicolumn{7}{|c|}{ t-test for Equality of Means } \\
\hline & \multirow[t]{2}{*}{ Sig. } & \multirow[t]{2}{*}{$\mathrm{t}$} & \multirow[t]{2}{*}{ Df } & \multirow[t]{2}{*}{$\begin{array}{l}\text { Sig. (2- } \\
\text { tailed) }\end{array}$} & \multirow{2}{*}{$\begin{array}{l}\text { Mean } \\
\text { Differe } \\
\text { nce }\end{array}$} & \multirow{2}{*}{$\begin{array}{l}\text { Std. } \\
\text { Error } \\
\text { Differe } \\
\text { nce }\end{array}$} & \multicolumn{2}{|c|}{$\begin{array}{l}95 \% \text { Confidence } \\
\text { Interval of the } \\
\text { Difference }\end{array}$} \\
\hline & & & & & & & Lower & Upper \\
\hline $\begin{array}{l}\text { Equal } \\
\text { variances } \\
\text { assumed }\end{array}$ & 0.1500 .703 & 0.629 & 18 & 0.538 & 0.300 & 0.477 & -0.703 & 1.303 \\
\hline $\begin{array}{l}\text { pretest Equal } \\
\text { variances } \\
\text { not } \\
\text { assumed }\end{array}$ & & 0.629 & 17.432 & 0.538 & 0.300 & 0.477 & -0.705 & 1.305 \\
\hline
\end{tabular}

In this hypothesis, Levon's test was first used to test for variance equality. It is considered that the value of sig is 0.150 and higher than 0.05 , thus assuming equality of variances is accepted. According to the offline and online groups enjoyed the same level of data distribution.

Result of the first question. The first question addressed in this study is defined as below: Does the online flipped model of instruction have any significant influence on the writing ability of upper-intermediate Iranian EFL learners? The next defined hypothesis for answering the first research question is: To examine the above question, researchers first ran the two-tailed independent t-test, as shown in the following table.

results of the t-test, the sig values are 0.477 and more than 0.05 . Therefore, the equality of averages is accepted at $95 \%$ confidence. In other words, the mean scores in two 
groups of online and offline in pretest were not significantly different.

Research hypothesis. There is a significant difference between posttest scores in the online and offline groups. To examine the above question, the independent t-test has been run. In this hypothesis, Levon's test was first used to test for variance equality. It is considered that the sig value is 0.00 , and less than 0.05 , thus assuming equality of variances is rejected. According to the results of the $\mathrm{t}$ test, the sig values are 0.00 and less than

Results of the second research question. The second research question addressed in this study is defined as below:

2. What are Iranian upper-intermediate EFL learners' attitudes toward implementing the flipped model of instruction?

As mentioned earlier, the volunteering learners from the experimental or online group participated in the interview conducted one by one after the treatment was over. Seven learners from this group participated in the interview. The following themes emerged from the interview:

Organization and Scheduling: The first theme arising from the interview data was the sense of organization, scheduling, and time-management. That is, the learners from the experimental group stated that the flipped instruction helps them organize their language learning in general and practicing writing in particular. It helped them identify the essential points taught in the previous session since they had to review lexical and grammatical points covered in the previous session before handling writing practice to avoid facing problems when writing. They stated that they had to look at the notes of the teacher's explanation or the Persian equivalents in their books - or their notebooks in a few
0.05 . Therefore, the equality of averages is rejected at $95 \%$ confidence. In other words, the mean scores in the two groups of offline and online posttests were significantly different. According to table 2, the mean of pretest of the offline group equals 13.70, and, in the posttest group, this value is 14.60. On the contrary, these values in the online group are 14.60 and 16.00, respectively. Therefore, it is indicated that the progress in the online group's performance is more evident than that in the offline group.

instances - and then start flipped learning programs. However, this approach helped them have a track of the new content for each lesson and session so that they could remember the points for classroom tests better.

Meaningful Review: As mentioned by the learners from the experimental group, they had a chance to review the passages regularly so that they could learn one aspect of writing as well as answering strategies over time rather than few days before the test or quizzes held by the teacher. They believed that the frequent review and established timed review by the teacher on flipped instruction helped them have an external pressure to be attentive to writing skills and course content as well. Another point was that, traditionally, students had to translate and write the meaning of the words in Persian, in most cases, next to the words and sentences in their books which was not too quick in doing writing activities or difficult to understand over time since they did not review them instantly after the session and came back to them sometime later so that they were out of the picture of the description given by the teacher. This flipped model instruction helped them change their study habit and focus on other strategies like guessing the meaning of 
words and taking the risk of paraphrasing sentences and choosing an answer without feeling ashamed when they chose a wrong answer.

Quick and Easy Material: The students believed that when the flipped model of instruction was presented in an organized format for each lesson and each session, they had no stress for the exams and tests, and they could have a wellestablished source of the writing. Moreover, they believed that they did not have to spend the time in class, taking notes, and could easily engage in doing exercises.

\section{Discussions}

The findings of the present study revealed that employing the strategy of flipped or inverted classroom imposed an exercised an impressive effect on upperintermediate EFL learner's writing ability. Thus, the results of this study are in harmony with other studies conducted by other researchers (Al-Harbi \&Alshumaimeri, 2016; Bhagat et al., 2016; Hung, 2015). Besides, Ting Hung (2015) stated that flipped instruction has the power of engaging learners at home, and the results of this study in the interview confirmed this study's finding. Moreover, Wentland (2004) declared that the flipped or inverted classroom could save time. Wentland stated that inverted instruction makes learners responsible for their

Concerning the first question, this study found out that learners can enhance their learning process by integrating technology and considering the possible effect of CALL in the learning environment. The results of the first question revealed that the flipped instruction of the online group has been more successful, and participants got better scores in their posttest in comparison to their counterparts, the offline group. In this regard, Tahmasebi and Rahimi (2013) stated
Prep-course Material: The EFL learners in the experimental group, who enjoyed the flipped instruction, stated that the presentation helped them to have a better understanding of the way they had to deal with the writing tasks on the exams. Since the exercises followed the presentation and practice phases were similar to those of the writing test of their quizzes and final test, the learners had a chance to get familiar with the same type of items on the quiz or final test.

learning, and instruction's orientation is toward learners, not teachers. Participants' expressions in the interview confirmed this study by Wentland (2004). Ebrahimi et al. (2013)investigated the impact of using technology and the Internet on the experience of students in their classroom environment and suggested that students in a technology-enhanced language learning classroom have a more positive attitude towards their classroom learning environment because it is more effective, learner-centered and motivating. Overall, these studies found out the positive effects of implementing flipped instruction in language learning, and this study confirmed their findings.

the possibility of using computer-assisted assessment as an alternative to the mainstream testing systems. The results also revealed that the experimental group had a significantly higher mean on the posttest than the control group. As the results indicated, it can be concluded that the upper-intermediate learners benefited the flipped technique and outperformed the learners who were deprived of the online flipped model of instruction. To assess the 
effect of flipped instruction on the learners' progress in writing, the posttest scores of the online group (treatment group) and the offline group (control group) were analyzed through statistical tests, and they were compared. The analysis of the posttest scores at the end of the study showed that online flipped instruction had a significantly positive impact on the posttest scores of the online group, while no significant changes were traced in the posttest scores of the offline group in comparison to their scores in the pretest. By the same token, Rahimi and Bigdeli (2014)Found that students taught using ICT techniques achieved a higher degree of self-regulation compared to those taught using conventional teaching methods. Such results, which confirmed the efficacy of flipped instruction on the EFL learners' language efficiency, were consistent with findings from similar studies conducted before the present study.

Concerning the second issue, which was aimed at defining the attitudes of EFL learners towards the flipped instruction

In general, flipped learning received the most supportive remarks from students in the research about the participation of the students in the classroom, allowing them the ability to plan for the exams, giving them a sense of structure and scheduling model, the results of the frequency analysis showed that EFL learners had mostly positive attitudes towards the flipped instruction model, and agreed that flipped instruction model would be useful in improving their writing abilities. Interview findings from the participants showed that most participants preferred to use flipped instruction online for language learning purposes. In general, the positive results of learning English writing among a community of EFL learners in a short period of study could be attributed to various factors, one of which is the enthusiasm and the new dimension of language learning by studying through this method. The results of the interview also showed the participants' eagerness to apply the process. This major result may have been attributed to different factors. One possible explanation for the results observed is that flipped classrooms allow students to enjoy more time in the classroom and have more time for interaction, learning, evaluation and exploration (Wentland, 2004).

concerning the views of students about the efficacy of the flipped classroom approach in enhancing their writing skills and supporting their self-learning opponents. Moreover, they had more and more time to spend on writing.

\section{Conclusions}

As mentioned earlier, the main goal of this study was to explore an effective way of teaching writing and inference making to EFL learners. After reviewing the available literature, two promising techniques were developed based on computer-assisted instruction.

A quasi-experimental design using pretest and posttest was used to compare flipped instruction and traditional instruction in terms of their impact on learners' writing. Considering the results of the statistical analysis presented above, the researchers found that flipped instruction was effective in both cases.

According to the findings of the study regarding the first and second null hypotheses of the present study, it was revealed that the learners receiving instruction in both groups could significantly improve their levels of writing. Although this pattern was visible in both groups, the results showed the superiority of the flipped instruction method used in the experimental 
method over the method in the control group.

Flipped model of instruction and EFL learners' writing proved to be interactive variables, and the link between the two and their impact on language learning is considered crucial in second language teaching and learning. On the other hand, as Cockrum (2013)states, this model offers a learning environment focused on the students to enhance their learning. The results of this study showed that not only did the flipped teaching model increase the performance of the students on writing, but it also improved their overall attitudes and beliefs towards writing and enhanced the enthusiasm and commitment of the students to the class.

There are two implications of the present study: one for teachers and the other for syllabus designers. According to the results of the current research, it can be argued that teachers at different levels should strongly rely on different computerassisted flipped instruction since it is proved to be more efficient.

Moreover, it is suggested that teacher training programs and teacher trainers attending pre-service or in-service programs encourage teachers to apply flipped instruction methods through computerassisted teaching. Also, they should have the candidates develop and practice flipped instruction so that they can master the application of these techniques.

Furthermore, syllabus designers and textbook developers are advised to incorporate computer-assisted flipped instructional material in their materials through devising companion electronic material, companion websites, and smartbooks. It is worth mentioning that both offline and online material could be useful for learners

\section{(C)Ali Rahimi \&MortezaHasheminasab}

Ali Rahimi, Ph.D. is a Full Professor at the School of Social Sciences and Languages, VIT University, Vellore, India. He was previously an Associate Professor of Applied Linguistics and Intercultural Studies at Bangkok University. He is the author of 14 books. He has also published extensively in various reputable international journals and has presented his articles at national and international conferences.

Morteza Hasheminasab is an MA student at English Department of University of Kashan, Iran. He has presented his papers at national conferences. He has 8 years of teaching experience. His areas of interest include Computer Assisted Language Learning, ELT, and LanguageProficiency.

\section{References}

Al-Harbi, S. S., \& Alshumaimeri, Y. A. (2016). The Flipped Classroom Impact in Grammar Class on EFL Saudi Secondary School Students' Performances and Attitudes. English Language Teaching, 9(10), 60-80 .
Beatty, K. (2013). Teaching \& researching: Computer-assisted language learning. Routledge .

Bhagat, K. K., Chang, C.-N., \& Chang, C.-Y. (2016). The impact of the flipped classroom on mathematics concept 
learning in high school. Journal of Educational Technology \& Society, 19(3), 134-142 .

Bishop, J. L .(2013) .The Flipped Classroom: A Survey of the Research. age, 23, 1 .

Brown, S. (2014). Open and Distance Learning: Case Studies from Education Industry and Commerce. Routledge .

Chapelle, C., \& Jamieson, J. (1986). Computer- assisted language learning as a predictor of success in acquiring English as a second language. TESOL quarterly, 20(1), 27-46.

Cockrum, T. (2013). Flipping your English class to reach all learners: Strategies and lesson plans. Routledge .

Ebrahimi, N. A., Eskandari, Z., \& Rahimi ,A. (2013). The Effects of Using Technology and the Internet on Some Iranian EFL Students' Perceptions of Their Communication Classroom Environment. Teaching English with technology, 13(1), 3-19.

Enfield, J. (2013). Looking at the impact of the flippedclassroom model of instruction on undergraduate multimedia students at CSUN. TechTrends, 57(6), 14-27.

Hubbard, P. (2009). Educating the CALL specialist. International Journal of Innovation in Language Learning and Teaching, 3(1), 3-15 .

Hughes, H\& ,.Bruce, C. S. (2013). International students' experiences of informed learning: A pedagogical case study. International Journal of Pedagogies and Learning, 8(2),106-119 .

Hung, H.-T. (2015). Flipping the classroom for English language learners to fosteractive learning. Computer Assisted Language Learning, 28(1), 81-96 .

Kiernan, P. J., \& Aizawa, K. (2004). Cell phones in task based learning-Are cell phones useful language learning tools? ReCALL, 16(1), 71-84 .

Lage, M. J., Platt, G. J., \& Treglia, M .(2000) . Inverting the classroom: A gateway to creating an inclusive learning environment. The Journal of Economic Education, 31(1), 30-43 .

Rahimi, A., \& Bigdeli, R. A. (2014). ICT and EFL Students' self-regulation mastery: Educational meat or poison. AsiaCALL Online Journal (ISSN 1936-9859) .

Salaberry, M. R. (2001). The use of technology for second language learning and teaching: A retrospective. The modern language journal, 85(1), 39-56 .

Tahmasebi, S., \& Rahimi, A. (2013). Computer-Assisted Assessment: Highlights and Challenges. Teaching English with technology, 13(2), 55-74 .

Timuçin, M. (2006). Implementing CALL in an EFL context. ELT journal, 60(3), 262271 .

Warschauer, M., \& Meskill, C. (2000). Technology and second language teaching. Handbook of undergraduate second language education, 15, 303-318 .

Wentland, D. (2004). A Guide for Determining Which Teaching Methodology to Utilize in Economic Education: Trying to Improve How Economic Information Is Commun-icated to Students. Education, 12 (4) 